\title{
Effects of maternal and offspring environmental conditions on growth, development and diapause in latitudinal yellow dung fly populations
}

\author{
Inon Scharf ${ }^{1,2, *}$, Stephanie S. Bauerfeind ${ }^{2,3}$, Wolf U. Blanckenhorn ${ }^{2}$, \\ Martin A. Schäfer ${ }^{2}$ \\ ${ }^{1}$ Department of Biology II, Ludwig Maximilian University of Munich, 82152 Planegg-Martinsried, Germany \\ ${ }^{2}$ Zoological Museum, Institute of Evolutionary Biology and Environmental Studies, University of Zurich, 8057 Zurich, Switzerland \\ ${ }^{3}$ Zoological Institute and Museum, University of Greifswald, 17489 Greifswald, Germany
}

\begin{abstract}
Extensive phenotypic plasticity can allow populations to persist in changing environments. Maternal effects represent one important but often neglected source of phenotypic plasticity. Mothers and offspring of 2 high- (northern Norway and central Sweden) and 2 low- (northern and southern Spain) latitude yellow dung fly Scathophaga stercoraria (Diptera: Scathophagidae) populations were exposed to cold $\left(12^{\circ} \mathrm{C}\right)$ and warm $\left(18^{\circ} \mathrm{C}\right)$ temperatures and to short ( $8 \mathrm{~h}$ light: $16 \mathrm{~h}$ dark) and long (16 h light:8 h dark) photoperiods in a fully blocked, split-brood common garden design of 8 treatment combinations. We also considered the role of energy content and size of the eggs in producing cross-generational maternal effects on offspring diapause, development time and growth rate. The incidence of diapause strongly declined towards the south, and the northernmost population grew and developed faster in response to perceived seasonal time constraints. There was strong population-specific phenotypic plasticity of all traits in response to offspring temperature and, more weakly, to offspring photoperiod, indicating a genetic basis of plasticity as well as genetic differentiation among populations. There were additional subtle cross-generational maternal effects exerted primarily by the lipid content of the eggs, largely independent of maternal treatment and population. Phenotypic plasticity of life-history traits in the yellow dung fly is predominantly influenced by the growing conditions during larval development, but populations can also respond to changing environments via trans-generational maternal effects.
\end{abstract}

KEY WORDS: Latitudinal clines $\cdot$ Maternal effects $\cdot$ Phenotypic plasticity $\cdot$ Photoperiod $\cdot$ Temperature

\section{INTRODUCTION}

Species with a wide geographical distribution typically experience a broad range of environmental conditions. The mechanisms with which, and the extent to which, populations are able to adapt to these conditions has gained renewed interest in light of recent climate change. The most evident, non-exclusive responses to varying environmental conditions are adaptive genetic divergence and phenotypic plasticity (Via \& Lande 1985, Schlichting 1986, Gotthard \& Nylin 1995, van Tienderen 1997, Nylin \& Gotthard 1998, Reznick \& Travis 2001, Liefting \& Ellers 2008, Bahrn- dorff et al. 2009, Blanckenhorn 2009). Although both processes have been often regarded as conceptually distinct, the recent literature stresses the importance of a more comprehensive view on how genetic divergence and phenotypic plasticity interact in allowing populations to persist in heterogeneous environments (reviewed in Pigliucci 2005, Räsänen \& Kruuk 2007, Crispo 2008).

Although clearly not all plastic responses are adaptive, adaptive plasticity can evolve when the environment is variable but predictable, producing the optimal phenotype for a given environment (Berrigan \& Scheiner 2004). Classic examples are the defense mor- 
phologies of water fleas and anuran tadpoles that are only expressed if predators are present during early development (e.g. Lüning 1992, Van Buskirk 2002). A special but common type of phenotypic plasticity consists of cross-generational parental (mostly maternal) effects, which are known to affect various life-history traits such as growth rate, development time, body size and shape, and fecundity and are typically proximately mediated via physiological or endocrine provisioning of embryos or eggs (Mousseau \& Dingle 1991, Mousseau \& Fox 1998, Fox \& Czesak 2000, Räsänen \& Kruuk 2007, Kjærsgaard et al. 2010, this Special). Such crossgenerational effects are particularly advantageous if the environmental conditions the offspring will face can be better predicted by the parents than by the offspring themselves, allowing parents to buffer the effects of environmental stressors on their offspring (Fox \& Mousseau 1998, Marshall \& Uller 2007).

Many species often face highly variable environmental conditions, even at a local scale (Liefting \& Ellers 2008). In such cases, the cues used to predict future environmental conditions should vary as well, potentially leading to different local responses to any particular cue. One of the most prominent environmental factors that varies systematically with latitude and altitude is season length, which imposes substantial time constraints on growth and development of organisms especially at high latitudes, often leading to winter diapause or quiescence (e.g. Blanckenhorn \& Fairbairn 1995, Blanckenhorn \& Demont 2004, Demont \& Blanckenhorn 2008, Fischer \& Karl 2010, this Special). The most common cue indicating seasonal change is the photoperiod, which is generally a more reliable predictor of seasonal change than are alternative cues such as temperature or humidity, at least at higher latitudes (Tauber et al. 1986, Danks 1987, Hanski 1988, Bradshaw \& Holzapfel 2007, Canale \& Henry 2010, this Special). Temperature and photoperiod are often correlated, however, so both variables may be used as cues across latitudes and can occasionally conflict with each other, leading to local differences in phenotypic plasticity (Mousseau \& Dingle 1991, De Block \& Stoks 2003, Tachibana \& Humata 2004). For example, initiation of diapause in southern populations may be prevented by warm temperatures despite a short photoperiod, while warm temperatures may have no effect on northern populations if photoperiod is short (Mousseau \& Dingle 1991). In general, females experiencing short photoperiods and/or low temperatures will increase the proportion of diapausing offspring (McWatters \& Saunders 1998, Mousseau \& Fox 1998). In addition to or in combination with diapause decisions, end-of-season time constraints imposed by seasonality typically also affect development time and growth rate of organisms (and ultimately body size), as many organisms, particularly insects, need to reach a particular life stage to successfully overwinter (e.g. Danks 1987, Blanckenhorn \& Fairbairn 1995, Blanckenhorn 1998a).

Plastic induction of winter diapause in response to seasonality, together with the necessary concomitant changes in growth and development, has been documented for various taxa including arthropods (Tauber et al. 1986, Danks 1987, McWatters \& Saunders 1998, Mousseau \& Fox 1998, Fox \& Czesak 2000). The strength of diapause induction varies with the stage at which the diapause occurs, being particularly strong for species with eggs as the resting stage (Danks 1987, Mousseau 1991, Mousseau \& Dingle 1991, Mousseau \& Fox 1998, Marshall \& Uller 2007). If diapause occurs in later stages, usually the diapausing stage itself or the stage immediately before it are most sensitive to diapause-inducing environmental cues. However, maternal cues may affect diapause responses as well as the growth and developmental trajectories of their offspring. Such cross-generational maternal effects are typically implemented via provisioning of eggs or offspring with physiological compounds or genetic information (Räsänen \& Kruuk 2007), reducing the occurrence of suboptimal phenotypic responses due to shortterm fluctuations in climatic conditions (Mousseau \& Dingle 1991, Denlinger 1998). The performance of offspring growing up in any particular environment will thus generally depend both on their own plastic responses to environmental cues and on any effects induced by the parents (primarily mothers) in response to the parental environment. The interaction between the offspring and the mother's environment in generating adaptive phenotypic plasticity has so far been underexplored in the literature (Blanckenhorn 2000, Stillwell \& Fox 2005, Räsänen \& Kruuk 2007). Clarifying the precise type or mechanism of phenotypic plasticity is of central importance for documenting and disentangling the various ways that organisms can adapt or acclimate to environmental (e.g. climate) change.

Here we report the results of a study on the yellow dung fly Scathophaga stercoraria (Diptera: Scathophagidae) in which mothers and offspring of 2 high(northern Norway and central Sweden) and 2 low(northern and southern Spain) latitude populations were exposed to 2 different temperatures (cold and warm) and 2 photoperiods (short and long) in a fully blocked, splitbrood design of 8 treatment combinations. Such experimental settings are particularly helpful in understanding the extent to which populations can adapt to changing environments (Chown et al. 2010, this Special). We explicitly considered the energy content and size of the (maternal) eggs to elucidate the possible mechanisms producing maternal effects. Previous research on this species has shown genetic differentiation in diapause propensity, development time, body size and growth rate 
across latitudinal populations in Europe (Blanckenhorn \& Demont 2004, Demont \& Blanckenhorn 2008, Demont et al. 2008), as well as high levels of phenotypic plasticity in these traits in response to food availability, temperature and photoperiod within populations (Blanckenhorn 1997, 1998a, 2000; reviewed in Blanckenhorn 2009). We specifically addressed: (1) the relative strength of maternal effects versus (direct) offspring plasticity in affecting the above life-history traits and offspring performance; (2) whether maternally induced plasticity and offspring plasticity are in the same or opposite directions; and (3) whether effects of temperature and photoperiod on plasticity are population-specific, and thus likely play a role in processes of local adaptation.

\section{MATERIALS AND METHODS}

\subsection{Study species and sampling sites}

The yellow dung fly Scathophaga stercoraria has adapted to colder climates and is distributed throughout north-temperate regions worldwide. Especially in the warmer southern areas of its distribution, the species inhabits higher altitudes (Blanckenhorn 2009). Females deposit their clutches of about 40 to 80 eggs into fresh dung of large mammals, mainly cattle, in which the larvae develop. Larvae face unpredictable spatio-temporal variation in their food source (dung) and are therefore regularly exposed to food limitation owing to intra- and interspecific competition and dung drying. Towards the end of the season flies are typically confronted with time constraints, as they have to reach the overwintering pupal stage before winter arrives (Blanckenhorn 1998a,b). Adults are sit-andwait predators of smaller flying insects, requiring an external protein source to develop sperm and eggs (anautogeny or income breeding; Foster 1967). Body size, growth and development depend on sex (with males being larger, growing faster and developing for longer), are highly plastic depending on food abundance and temperature, and show moderate heritability (Blanckenhorn 1997, 1998a, 2002, 2009).

Flies were collected from 2 northern and 2 southern populations spanning the extent of their range in Europe (from north to south; Table 1): (1) Tromsø, Norway (collected in August 2007); (2) Uppsala, Sweden (August 2007); (3) the Pyrenees mountains, Spain (March 2007); and (4) the Sierra Nevada mountains, Spain (March 2007).

\subsection{Experimental treatments}

Flies of all 4 populations were raised and held using standard methods (Blanckenhorn 1997) in a large climate chamber at $18^{\circ} \mathrm{C}$ and $12 \mathrm{~h}$ light: $12 \mathrm{~h}$ dark photoperiod for at least 2 generations. Our experiments were conducted with fourth and sixth generation flies (northern and southern populations, respectively). After adult emergence, the mothers of our experimental generation were randomly distributed into 4 different environments characterized by short or long photoperiod and low or high temperatures: (1) $12^{\circ} \mathrm{C}, 8 \mathrm{~h}$ light:16 h dark; (2) $12^{\circ} \mathrm{C}, 16 \mathrm{~h}$ light:8 h dark; (3) $18^{\circ} \mathrm{C}$, $8 \mathrm{~h}$ light:16 h dark; and (4) $18^{\circ} \mathrm{C}, 16 \mathrm{~h}$ light:8 h dark. All males were always kept at $18^{\circ} \mathrm{C}$ and $12 \mathrm{~h}$ light: $12 \mathrm{~h}$ dark. When females had reached sexual maturity after about $14 \mathrm{~d}$, they were mated randomly with a male originating from the same population. We used 46 mothers from Tromsø, 56 from Uppsala, 63 from the Sierra Nevadas and 53 from the Pyrenees (218 in total). The clutch of each female was counted and then split into 4 transparent plastic containers $(3.5 \times 3.5 \times 5.5 \mathrm{~cm})$ with an average of 10 eggs per container (range $=7$ to 14 ). Each container was filled with $\sim 40 \mathrm{~g}$ of previously frozen fresh cattle dung (cf. Amano 1983). Flies were fed overabundant food as larvae and adults to provide identical optimal conditions for growth and to avoid responses to food stress, which may differ among populations. The offspring of each female were subsequently divided between the same 4 photoperiod/ temperature combinations and raised to adulthood. Thus the maternal and offspring climatic conditions were fully crossed. We checked for adult fly eclosions every other day during the first 3 mo after the first flies emerged to obtain egg-to-adult development times. Afterwards, flies developing at $12^{\circ} \mathrm{C}$ were checked 2 to 3 times a week for a period of 8 mo to score any diapausing offspring. Any adults emerging after $75 \mathrm{~d}$ were considered as diapausing, following Blancken-

Table 1. Coordinates, elevation, mean daily temperature (January, July), number of daylight hours (December, June) and estimated winter length (days of average temperature below $5^{\circ} \mathrm{C}$, the growth threshold of the yellow dung fly) at the 4 collection points

\begin{tabular}{|llcccc|}
\hline Location & Coordinates & $\begin{array}{c}\text { Eleva- } \\
\text { tion } \\
(\mathrm{m})\end{array}$ & $\begin{array}{c}\text { Mean } \\
\text { temperature } \\
\left({ }^{\circ} \mathrm{C}\right)\end{array}$ & $\begin{array}{c}\text { Daylight } \\
(\mathrm{h})\end{array}$ & $\begin{array}{c}\text { Winter } \\
\text { length } \\
(\mathrm{d})\end{array}$ \\
\hline Tromsø, Norway & $69.66^{\circ} \mathrm{N}, 18.97^{\circ} \mathrm{E}$ & 5 & $-10.7,12.6$ & 0,24 & 243 \\
Uppsala, Sweden & $59.85^{\circ} \mathrm{N}, 17.63^{\circ} \mathrm{E}$ & 16 & $-4.1,17.1$ & $5.5,18.5$ & 178 \\
Pyrenees & $42.25^{\circ} \mathrm{N}, 1.90^{\circ} \mathrm{E}$ & 830 & 5,25 & 9,15 & 97 \\
$\quad \begin{array}{l}\text { Mountains, Spain } \\
\text { Sierra Nevada } \\
\text { Mountains, Spain }\end{array}$ & $37.20^{\circ} \mathrm{N}, 3.20^{\circ} \mathrm{W}$ & 1290 & $6.7,25.1$ & $9.5,14.5$ & 91 \\
\hline
\end{tabular}


horn (1998b) and Demont \& Blanckenhorn (2008). Hind tibia length (HTL) of all mothers and offspring was measured as a standard estimate of body size in this species (e.g. Blanckenhorn 1998a) by taking digitized photographs. Growth rates were then estimated by dividing HTL by development time. Our data set comprised a total of 2313 individual offspring flies. However, not all flies were used in every analysis. For example, analysis of diapause incidence was performed only on flies growing in the colder temperature $\left(12^{\circ} \mathrm{C}\right)$, and analysis of development time included only non-diapausing individuals (see statistical tables in Section 3). Also note that analysis of development time and growth rate was performed on family means.

\subsection{Physiological analysis}

We photographed a sample of 5 eggs per mother's clutch to estimate mean egg volume using the software IMAGEJ. We further measured energy content as reflected in protein, lipid and glycogen content using the photometric methods of Van Handel \& Day (1988). Physiological analyses were performed on groups of 10 eggs per clutch, yielding one estimate for lipid, glycogen and protein content for each mother (i.e. family). Note that glycogen and lipid content can be derived from the same sample, while protein required another sample of 10 eggs (Van Handel \& Day 1988). Groups of eggs were homogenized in $200 \mu \mathrm{l}$ of $2 \% \mathrm{Na}_{2} \mathrm{SO}_{4}$, which absorbs and precipitates the glycogen. Glycogen was then quantified photometrically by anthrone reaction with $0.1 \%$ glucose in $25 \% \mathrm{EtOH}$ as the calibration standard (Van Handel 1985a). After a (1:1) chloroformmethanol extraction, lipid content was measured using a vanillin-phosphoric acid reaction with $0.1 \%$ soybean oil in chloroform as the standard (Van Handel 1985b). The total (i.e. structural plus free) protein content was measured as total nitrogen by Nesslerization of Kjeldahl digests of eggs with $0.1 \mathrm{~N}$ ammonium sulfate as the standard (Minari \& Zilversmit 1963, Van Handel 1985b), and was then back-calculated to the amount of protein by multiplying by 6.25 (assuming $16 \%$ average nitrogen content of all amino acids). The necessary photometric readings were always performed twice for each sample, which were averaged. To facilitate direct comparison, the energetic values of all components were converted to calories $(1$ calorie $=4.187$ Joules, corresponding to $250 \mu \mathrm{g}$ protein and $110 \mu \mathrm{g}$ lipids).

\subsection{Statistical analysis}

Diapause incidence of all offspring emerged at $12^{\circ} \mathrm{C}$ only (as only a handful of flies entered diapause when grown at $18^{\circ} \mathrm{C}$ ) was analyzed using binary logistic regression, disregarding sex (diapause or not; $\mathrm{N}=$ 1770). Population origin, maternal temperature, maternal photoperiod and offspring photoperiod plus their interactions were entered as fixed discrete factors, and (the mother's) egg volume and egg content (lipids, glycogen and protein) as continuous covariates. We further entered the mother's identity (i.e. family) as a discrete nested random effect to remove variation among families, which was the relevant error term for the maternal traits (cf. Table 2). All 3-way and higherlevel interactions were not significant and therefore removed from the final model, keeping only all 2-way interactions among fixed factors (whether significant or not) for symmetry reasons.

Development time and growth rate (=HTL/development time) were analyzed by analogous GLMs, using values averaged over all individuals of a particular sex within a family within treatment combinations as individual data points (family means: individuals per family ranging from 1 to 5, N = 163 families; cf. Table 3). This amounts to a quasi-genetic analysis. Separate analysis of body size was therefore redundant and is not presented. We used non-diapausing individuals only for this analysis, because growth rates as defined above make little sense once individuals have diapaused. Again we entered population of origin, maternal temperature, maternal photoperiod, offspring photoperiod and now also offspring temperature plus their interactions as discrete fixed factors, the mother's identity (family) as a discrete nested random factor, and egg volume and egg content (lipids, glycogen and protein) as continuous covariates. As Scathophaga stercoraria is a dimorphic species, sex had to be taken into account in the model to remove sex differences, but only as a main effect so as not to further complicate the analysis, because sex-specific effects in this context for this species are well known (Blanckenhorn 1998a, Teuschl et al. 2007, Demont et al. 2008). Again, all 3way and higher-level interactions were not significant and thus removed from the final model, keeping only 2 -way interactions. We used purely descriptive nonparametric smoothing functions to visualize the actual relationship between continuous variables (cf. Figs. 2 $\& 5$ ), even though in the models above they were entered as linear effects.

\section{RESULTS}

\subsection{Diapause incidence}

Diapause incidence at $12^{\circ} \mathrm{C}$ strongly decreased from north to south (significant population effect; Table 2, Fig. 1). Overall, diapause frequencies were lower in the 
Table 2. Scathophaga stercoraria. Binary logistic regression for the effect of maternal traits and treatments (top levels; tested against error 1) and offspring traits (bottom levels; tested against global error) on the diapause incidence of yellow dung flies. All 3-way and higher-order interactions were not significant and therefore not included. Mat.: maternal; Off.: offspring. Bold: significant; italics: marginally non-significant

\begin{tabular}{|lccc|}
\hline & \multicolumn{4}{c}{ Diapause incidence } \\
Source & $\mathrm{df}$ & $\chi^{2}$ & $\mathrm{p}$ \\
\hline Population & 3 & 10.99 & $\mathbf{0 . 0 1 2}$ \\
Mat. temperature & 1 & 1.75 & 0.186 \\
Mat. photoperiod & 1 & 0.20 & 0.657 \\
Population $\times$ Mat. temperature & 3 & 3.53 & 0.317 \\
Population $\times$ Mat. photoperiod & 3 & 6.64 & 0.156 \\
Mat. temperature $\times$ Mat. photoperiod & 1 & 0.05 & 0.832 \\
Egg volume & 1 & 3.40 & 0.065 \\
Egg protein & 1 & 0.01 & 0.985 \\
Egg lipid & 1 & 4.78 & $\mathbf{0 . 0 2 9}$ \\
Egg glycogen & 1 & 0.23 & 0.635 \\
Mat. family (error 1) & 171 & 809.75 & $<\mathbf{0 . 0 0 1}$ \\
Off. photoperiod & 1 & 39.67 & $<\mathbf{0 . 0 0 1}$ \\
Population $\times$ Off. photoperiod & 3 & 80.89 & $<\mathbf{0 . 0 0 1}$ \\
Mat. temperature $\times$ Off. photoperiod & 1 & 0.02 & 0.964 \\
Mat. photoperiod $\times$ Off. photoperiod & 1 & 0.2 & 0.656 \\
Global error & 1576 & & \\
\hline
\end{tabular}

long (16 h light:8 h dark) photoperiod (significant offspring photoperiod effect; Table 2), except in the northernmost population (significant population by offspring photoperiod interaction; Table 2, Fig. 1). There was also significant genetic variation among families in diapause incidence, but this was expected and of little interest here (significant maternal family effect; Table 2). Finally, the tendency to diapause increased with lipid content of the egg (positive correlation) and at the same time tended to decrease with egg volume (negative

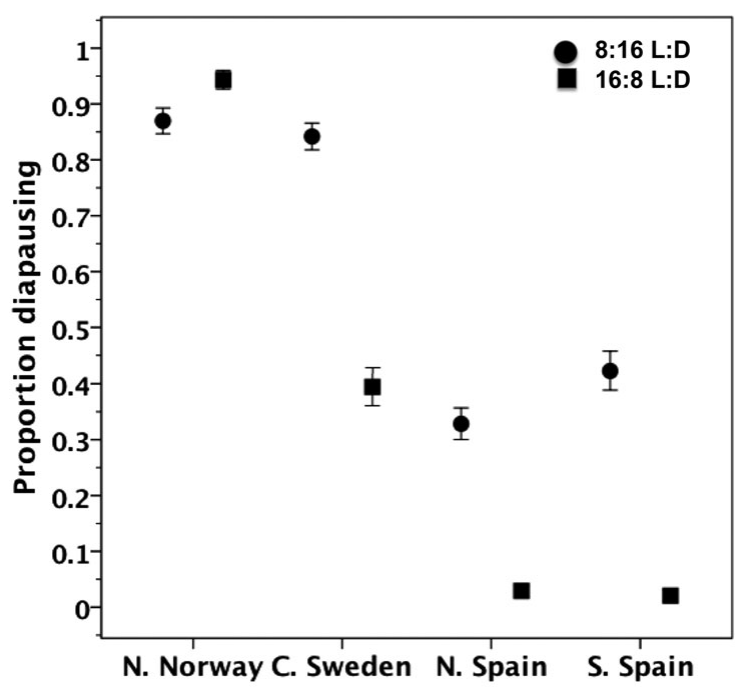

Fig. 1. Scathophaga stercoraria. Mean $( \pm \mathrm{SE})$ proportion of diapausing offspring individuals for 4 latitudinal populations arranged from north to south exposed to $8 \mathrm{~h}$ light:16 h dark (circles) and $16 \mathrm{~h}$ light:8 $\mathrm{h}$ dark (squares) offspring photoperiod

correlation), even though all energy components were positively correlated with each other and with egg volume $(0.21<\mathrm{r}<0.55$, all $\mathrm{p}<0.05)$. The effect of egg lipid content was significant and that of egg volume was marginally non-significant, (Table 2, Fig. 2). We tested whether any of the energy components or egg volume interacted with the maternal photoperiod and temperature treatments, which would demonstrate a possible direct mechanism by which females might implement cross-generational maternal effects in response to specific environmental cues. No such interactions were detected and they were subsequently removed
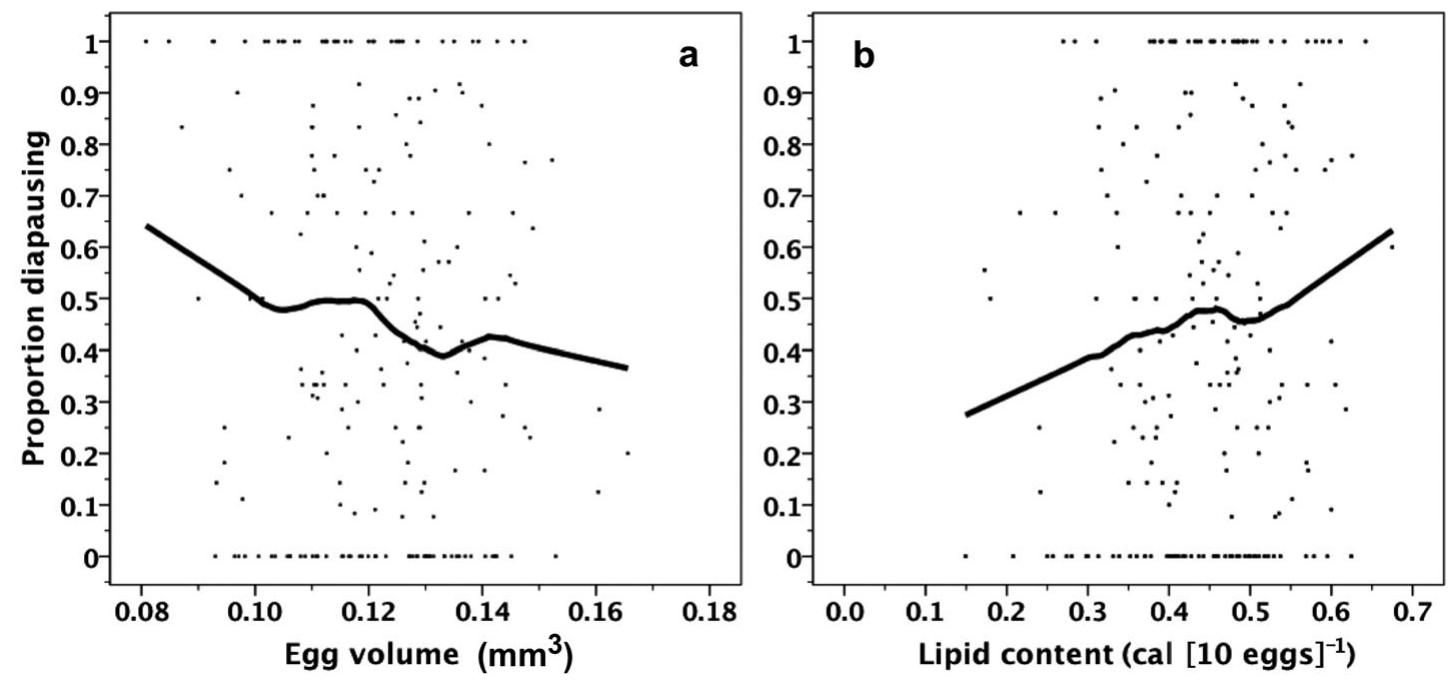

Fig. 2. Scathophaga stercoraria. Mean proportion of diapausing offspring individuals per treatment combination as a function of (a) egg volume and (b) egg lipid content, with smoothing splines to visualize the actual relationship 
from the model. However, egg volume and all energy components were affected by maternal treatment in that they were lowest when mothers had experienced high temperature and long photoperiod, i.e. summer conditions, and higher for all other treatment combinations (data not shown). All other effects did not significantly influence diapause incidence. In particular, we found neither effects of maternal temperature or photoperiod on diapause incidence, nor any maternal treatment by offspring treatment interactions, even when all covariates were removed.

\subsection{Development time and growth rate}

As expected (cf. Demont et al. 2008), northern populations grew faster and developed more quickly as they faced seasonal time constraints (significant effect of population; Table 3, Fig. 3). Interestingly, growth rates were lower and development times longer in the 2 southern populations when the mother developed to maturity at warm $\left(18^{\circ} \mathrm{C}\right)$ compared to cool $\left(12^{\circ} \mathrm{C}\right)$ temperatures, whereas the opposite (or no change) occurred in the 2 northern populations (significant population by maternal temperature interaction; Table 3, Fig. 3). This suggests that offspring of mothers developing under summer conditions respond as if they were time constrained in the north but not in the south. Sex and offspring temperature strongly and significantly affected growth and development (see effect sizes in Table 3), but these effects are standard and already known (e.g. Blanckenhorn 1997, 1998a). There was again significant genetic variation among families in growth rate and development time, which is also well known for this species and discussed elsewhere (Blanckenhorn 1998a, 2002). Both traits investigated showed a significant offspring temperature by offspring photoperiod interaction, for all populations (Table 3, Fig. 4): at the high temperature $\left(18^{\circ} \mathrm{C}\right)$ offspring grew faster and developed more quickly (i.e. the expected response to time constraints) at short ( $8 \mathrm{~h}$ light:16 h dark) photoperiods, whereas at the low temperature $\left(12^{\circ} \mathrm{C}\right)$, when growth and development are much slower in general, offspring grew faster and developed more quickly at long (16 h light:8 h dark) photoperiods. Thus in both cases faster growth and development occurred at the more unnatural combination of cues (warm temperature combined with short photoperiod, and cool temperature combined with long photoperiod). Again, no effects of maternal treatment, and no interactive effects between maternal and offspring treatments, on growth or development were found. Finally, offspring growth rate decreased, and development time increased, as the eggs from which they hatched contained more lipids (significant linear egg lipid effect; Table 3, Fig. 5). Finally, we again

Table 3. ANOVA results for growth rate and development time (generalized linear model, based on family mean data) as a function of maternal traits and treatments (top levels; tested against error 1) and offspring traits (bottom levels; tested against global error) of yellow dung flies Scathophaga stercoraria. All 3-way and higher-order interactions were not significant and therefore not included. Bold: significant

\begin{tabular}{|c|c|c|c|c|c|c|c|c|}
\hline \multirow[b]{2}{*}{ Source } & \multirow[b]{2}{*}{ df } & \multicolumn{2}{|c|}{ - Growth rate } & \multirow[b]{2}{*}{ Effect size } & \multirow{2}{*}{$\mathrm{df}$} & \multicolumn{2}{|c|}{-Development tim } & \multirow{2}{*}{ Effect size } \\
\hline & & $F$ & $\mathrm{p}$ & & & $F$ & $\mathrm{p}$ & \\
\hline Population & 3 & 4.11 & 0.008 & 0.071 & 3 & 3.77 & 0.012 & 0.065 \\
\hline Mat. temperature & 1 & 1.1 & 0.295 & 0.007 & 1 & 0.72 & 0.398 & 0.004 \\
\hline Mat. photoperiod & 1 & 0.7 & 0.403 & 0.004 & 1 & 0.91 & 0.341 & 0.006 \\
\hline Population $\times$ Mat. temperature & 3 & 3.49 & 0.017 & 0.022 & 3 & 3.3 & 0.022 & 0.033 \\
\hline Population $\times$ Mat. photoperiod & 3 & 0.29 & 0.833 & 0.002 & 3 & 0.22 & 0.874 & 0.002 \\
\hline Mat. temperature $\times$ Mat. photoperiod & 1 & 0 & 0.964 & 0 & 1 & 0.23 & 0.631 & 0.001 \\
\hline Egg volume & 1 & 0.53 & 0.467 & 0.003 & 1 & 0.08 & 0.775 & 0.001 \\
\hline Egg protein & 1 & 0.03 & 0.856 & 0 & 1 & 0.14 & 0.713 & 0.001 \\
\hline Egg lipid & 1 & 7.65 & 0.006 & 0.043 & 1 & 4.19 & 0.042 & 0.045 \\
\hline Egg glycogen & 1 & 0.44 & 0.507 & 0.003 & 1 & 0.98 & 0.323 & 0.006 \\
\hline Mat. family (error 1) & 162 & 1.46 & 0.001 & 0.285 & 162 & 1.61 & $<0.001$ & 0.301 \\
\hline Sex & 1 & 753.09 & $<0.001$ & 0.559 & 1 & 185.61 & $<0.001$ & 0.235 \\
\hline Off. temperature & 1 & 3457.1 & $<0.001$ & 0.853 & 1 & 4909.1 & $<0.001$ & 0.89 \\
\hline Off. photoperiod & 1 & 18.11 & $<0.001$ & 0.03 & 1 & 0.79 & 0.374 & 0.001 \\
\hline Off. temperature $\times$ Off. photoperiod & 1 & 176.37 & $<0.001$ & 0.229 & 1 & 158.34 & $<0.001$ & 0.207 \\
\hline Population $\times$ Off. temperature & 3 & 1.21 & 0.304 & 0.006 & 3 & 2.93 & 0.033 & 0.014 \\
\hline Population $\times$ Off. photoperiod & 3 & 0.91 & 0.437 & 0.005 & 3 & 0.69 & 0.557 & 0.003 \\
\hline Mat. temperature $\times$ Off. temperature & 1 & 2.07 & 0.151 & 0.003 & 1 & 0.94 & 0.333 & 0.002 \\
\hline Mat. temperature $\times$ Off. photoperiod & 1 & 0 & 0.99 & 0 & 1 & 2.49 & 0.115 & 0.004 \\
\hline Mat. photoperiod $\times$ Off. temperature & 1 & 0 & 0.95 & 0 & 1 & 0.41 & 0.521 & 0.001 \\
\hline Mat. photoperiod $\times$ Off. photoperiod & 1 & 0.06 & 0.814 & 0 & 1 & 2.72 & 0.099 & 0.004 \\
\hline Global error & 594 & & & & 605 & & & \\
\hline
\end{tabular}



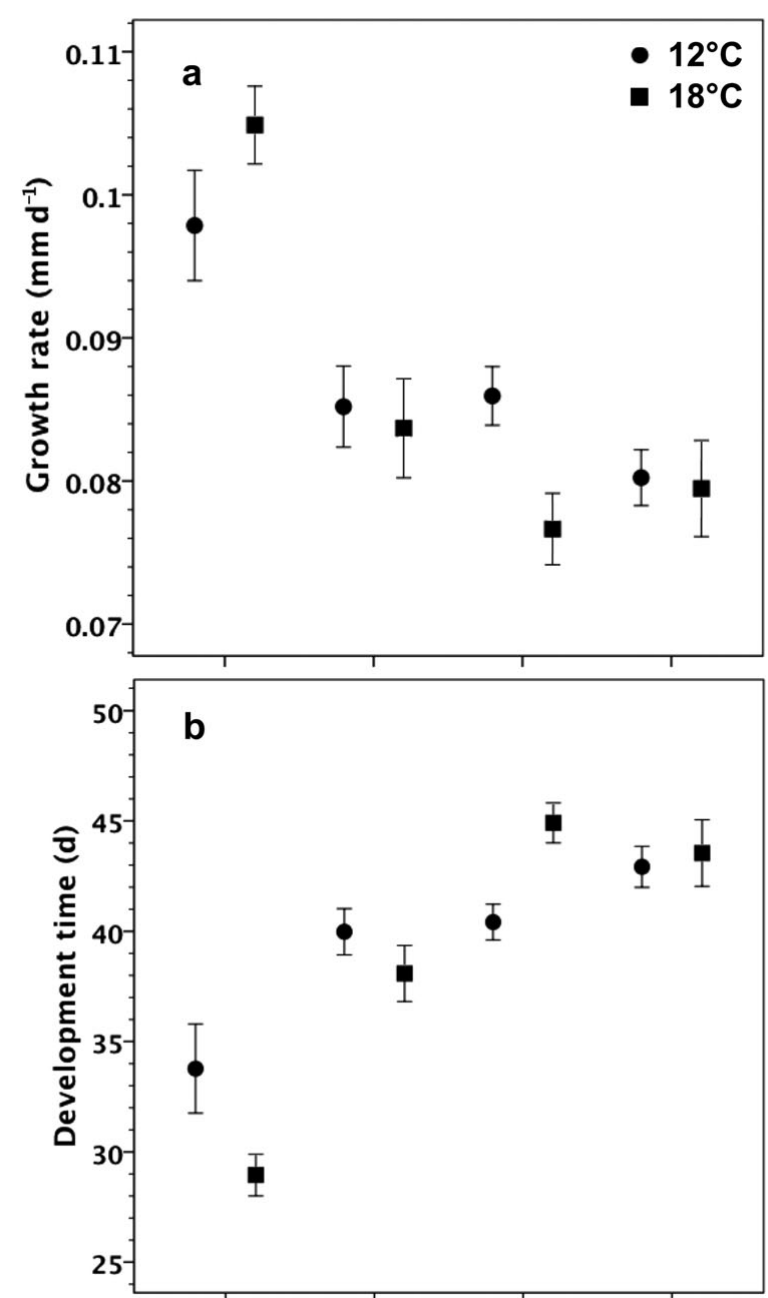

N. Norway C. Sweden N. Spain S. Spain

Fig. 3. Scathophaga stercoraria. Mean (a) offspring growth rate and (b) development time ( $\pm \mathrm{SE}$; both sexes combined) for 4 latitudinal populations arranged from north to south at $12^{\circ} \mathrm{C}$ (circles) and $18^{\circ} \mathrm{C}$ (squares) maternal temperature

explicitly tested whether any of the energy components or egg volume interacted with the maternal photoperiod and temperature treatments, but no such interactions were detected (so they were dropped from the final model). However, when dropping all covariates from the model, the main effect of maternal temperature on both growth rate and development time became significant, suggesting that the temperaturespecific maternal effects are at least in part mediated by the egg lipids provisioned by the mother.

\section{DISCUSSION}

Temperature and photoperiod are 2 of the most important environmental factors affecting an organism's behavior, life history and morphology (Huey \& King-
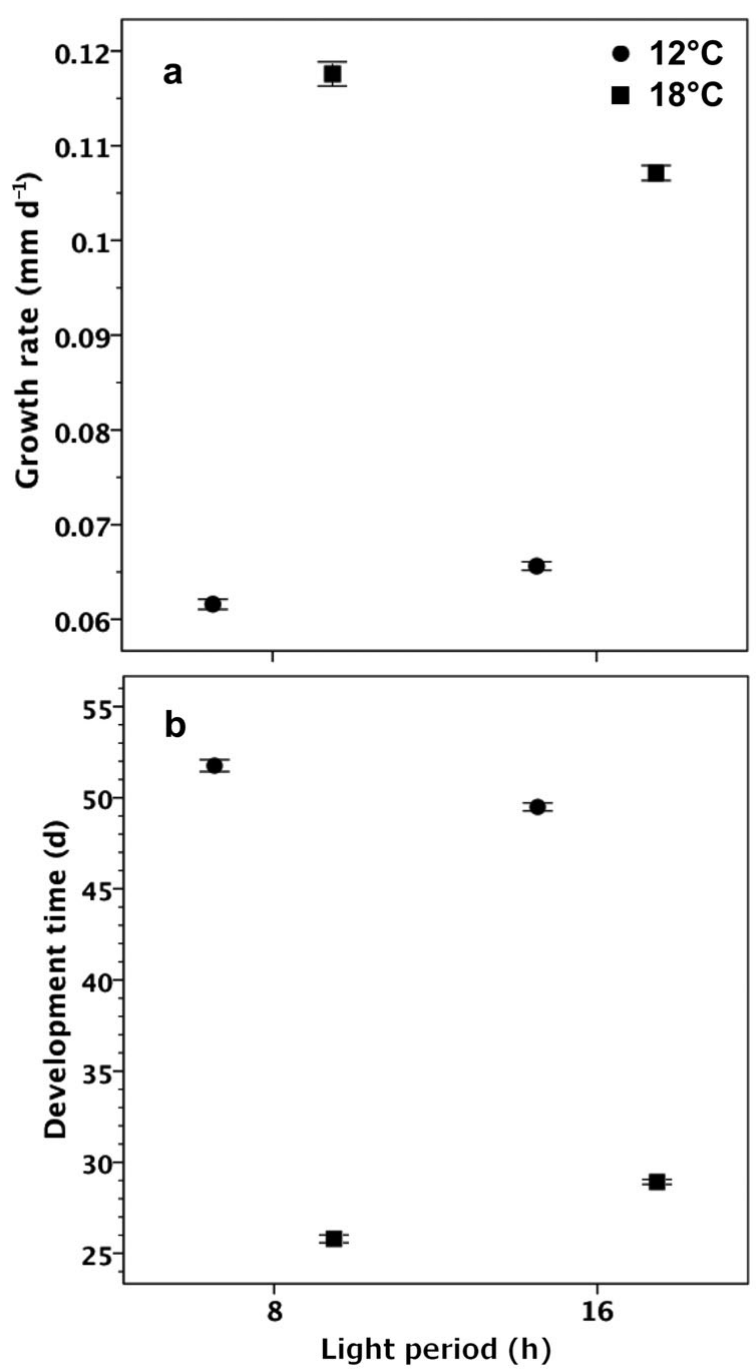

Fig. 4. Scathophaga stercoraria. Mean (a) offspring growth rate and (b) development time $( \pm \mathrm{SE}$; both sexes combined) at $12^{\circ} \mathrm{C}$ (circles) and $18^{\circ} \mathrm{C}$ (squares) offspring temperature and $8 \mathrm{~h}$ light:16 h dark and $16 \mathrm{~h}$ light:8 h dark offspring photoperiod

solver 1989, Angilletta et al. 2004, Bradshaw \& Holzapfel 2007). We investigated, using 4 latitudinal yellow dung fly populations, how temperature and photoperiod, as experienced during the life stage of the offspring and, independently, by the mother, interact to produce phenotypic plasticity in diapause, development time and growth rate, the key life-history traits in the context of seasonality (Nylin \& Gotthard 1998). Our results show strong phenotypic plasticity in response to offspring temperature and, more weakly, offspring photoperiod treatment. We also observed even weaker maternal effects produced primarily by the lipid content of the eggs, largely independent of maternal treatment. Furthermore, the effect of maternal temperature on growth and development rate varied among populations. However, we found no interactive effects be- 


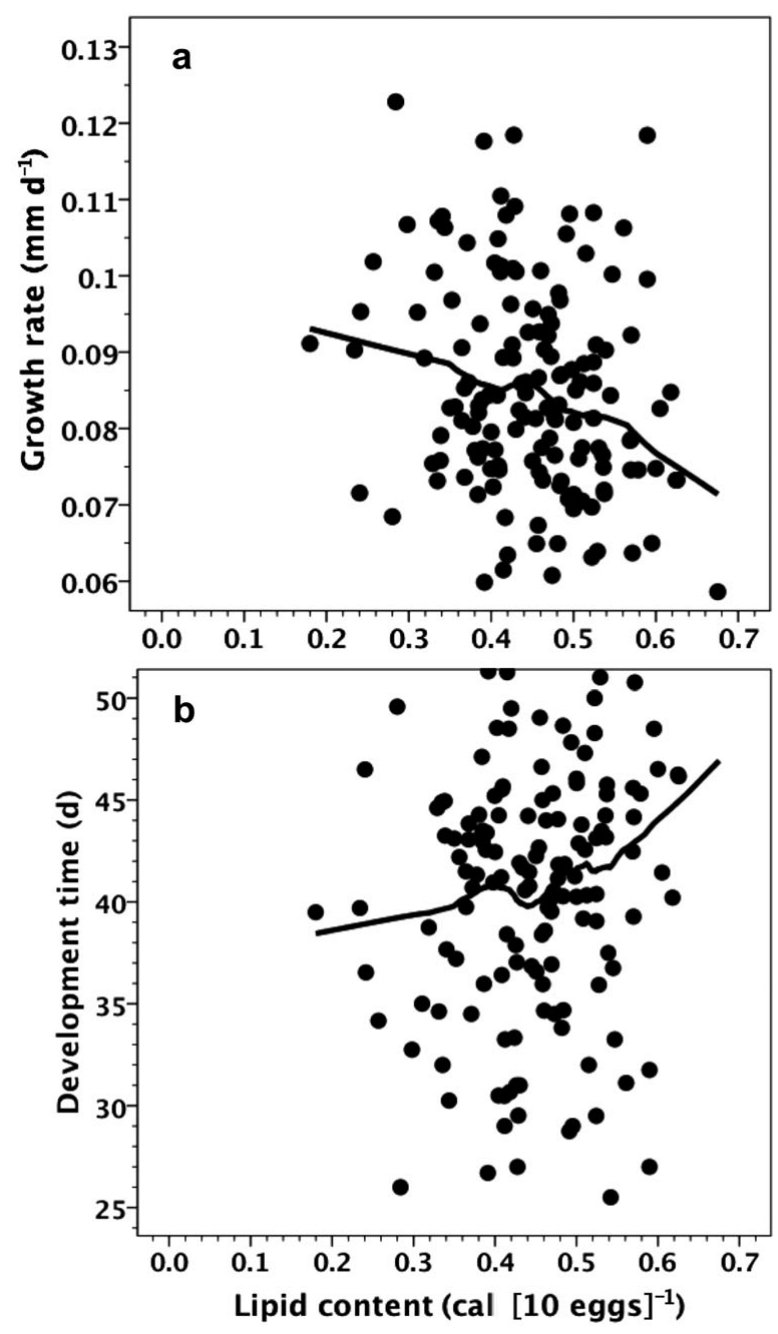

Fig. 5. Scathophaga stercoraria. Mean (a) offspring growth rate and (b) development time per family (both sexes combined) as a function of egg lipid content, with smoothing splines to visualize the actual relationship

tween maternal and offspring treatments on any of the life-history variables examined. As our flies were kept in the laboratory for 3 to 5 generations prior to our experiments, it is possible that some genetic variation was lost or some laboratory adaptation occurred, although these processes would be minor compared to the lifehistory differences we found.

The northern Scandinavian populations showed much higher incidence of diapause at $12^{\circ} \mathrm{C}$ than did the southern Spanish populations (Demont \& Blanckenhorn 2008). Flies from the south hardly entered diapause at all when the offspring photoperiod indicated long summer days (Fig. 1; cf. Mousseau \& Dingle 1991). Interestingly and conversely, the northernmost population from Norway showed higher diapause incidence at long, summer photoperiods. An adaptive explanation can be provided if we assume that, for the univoltine northern populations, a short ( $8 \mathrm{~h}$ light:16 $\mathrm{h}$ dark) photoperiod indicates spring, rather than autumn as is likely the case further south, with more rather than fewer days left before winter than when facing a long ( $16 \mathrm{~h}$ light: $8 \mathrm{~h}$ dark) summer photoperiod (Fig. 1). This suggestion remains to be tested in other univoltine insects. It is important to note that the climatic difference in nature between the 2 northern populations is much greater than that between the 2 southern populations (Table 1), potentially explaining the difference in response between Tromsø and Uppsala flies.

In any case, offspring photoperiod strongly and differentially affected diapause responses of all populations in an explainable way, showing that when considering populations along a latitudinal gradient, photoperiod is important for winter diapause decisions, contrary to what Blanckenhorn (1998b) concluded from his studies on one Swiss population. Nevertheless, overall our results are in disagreement with the general notion that in temperate insect species photoperiod is the dominant cue for the onset of diapause, with all other cues including temperature merely serving as modifiers (Hairston \& Kearns 1995, Gomi 1997, but see Mousseau \& Dingle 1991, Canale \& Henry 2010). Congruent with the diapause results, northern populations under more seasonal time constraints also showed the expected and presumably adaptive accelerated growth and development (Abrams et al. 1996, Blanckenhorn \& Demont 2004, Demont et al. 2008; Fig. 3).

While the effects of offspring temperature and photoperiod were substantial for all life-history traits, maternal treatment had no, or only weak, crossgenerational effects on the life-history traits considered. Maternal temperature was the only treatment showing a weak effect on growth rate and development time (but not diapause), and this varied among populations (Fig. 3). When mothers developed to maturity (and laid eggs) at $18^{\circ} \mathrm{C}$-indicating summer conditions - the offspring of the northernmost Scandinavian population(s) grew and developed more quickly, indicating time constraints, whereas offspring of the southern populations grew and developed more quickly when their mothers grew up at the cooler temperature $\left(12^{\circ} \mathrm{C}\right)$, presumably indicating late season (autumn) conditions to them. This result is congruent with the switch across the latitudinal populations in the effect of offspring photoperiod on diapause discussed above (cf. Fig. 1). Tromsø has a very short summer, so when temperatures are already at the peak of $18^{\circ} \mathrm{C}$ (note that average summer temperature is below $13^{\circ} \mathrm{C}$; Table 1 ), there is no time for another generation, which takes at least a month. This is probably not the situation in Uppsala, and surely not the case in Spain. This interactive effect shows that maternal temperature (but not photoperiod) is used as a seasonal cue in addition to 
offspring conditions (Tauber et al. 1986, Danks 1987), which may have a substantial influence on life histories, especially in southern populations (McWatters \& Saunders 1998).

Although the present study did not reveal many cross-generational maternal effects in response to manipulated maternal treatments (temperature and photoperiod), the lipid content of the eggs provisioned by the mother consistently affected offspring performance. Diapause incidence generally increased with lipid content of the eggs from which the offspring hatched (Fig. 2), while growth rate of non-diapausing offspring decreased and development time increased with egg lipid content (Fig. 5). At the same time we detected an independent weak (marginally nonsignificant) trend for diapause incidence to decrease as eggs became larger (Fig. 2), even though the content of all nutrients (lipids, protein and glycogen) correlated positively with egg size. These cross-generational effects were largely unspecific, as they generally occurred in all populations and for all treatments. However, growth and developmental trajectories of the offspring seem at least partly mediated by the egg lipids provisioned by the mother in response to her specific temperature environment, as maternal temperature significantly affected both growth rate and development time when all covariates (including lipids and egg size; cf. Fig. 2) were removed from the model. In any case, yellow dung fly offspring hatching from smaller eggs containing more lipids are more likely to enter pupal diapause as winter approaches, while more lipids result in slower growth and longer development in non-diapausing individuals. Typically, the diapausing stage is characterized by tremendously increased lipid reserves that are accumulated during the preparatory phase immediately before diapause (Downer \& Matthews 1976). Lipids are thus the primary nutrient reserves affecting survival over winter as well as during the initial stages of egg development before the larva hatches. Lipids presumably also positively affect at least early performance of the hatching larvae, especially under harsh conditions (Tauber et al. 1986, Danks 1987, e.g. Blanckenhorn 1994). The same is generally assumed for larger eggs (Nylin \& Gotthard 1998, Murry et al. 2008, e.g. Blanckenhorn 2000). Thus the smaller and weaker offspring might preferably enter diapause in order to compete in the more favorable spring season, when food is more abundant.

Yellow dung flies overwinter as pupae and need to feed as larvae beforehand. Therefore, effects of egg size and nutrients on overwintering should be weak and masked by any presumably stronger effects of early growth and development during the intermediate larval stage. Weak effects of egg size on larval performance agree with 2 previous studies of yellow dung flies (Jann \& Ward 1999, Blanckenhorn 2000), but contradict several other studies of other species demonstrating the importance of maternal investment for offspring fitness in large eggs with high energy content, even at later stages (e.g. Azevedo et al. 1997, Kaplan 1998). The cross-generational maternal effects of egg lipids and egg size on offspring we obtained are thus a little difficult to interpret in an adaptive framework, given the life history of yellow dung flies. What is clear is that the mother, through egg provisioning, can influence the diapause decision of her offspring even at a much later stage (the pupa).

In summary, while reiterating previously known phenotypic plasticity in response to temperature (Blanckenhorn 1997, 1998a, 2009), the present study revealed a strong and differentiated effect of photoperiod on diapause responses of latitudinal populations that can be interpreted in an adaptive way, a novel finding somewhat contrary to previous conclusions based on one Swiss population (Blanckenhorn 1998b). Importantly, the present study additionally demonstrated novel, albeit subtle, cross-generational maternal effects affecting diapause, growth and development in this species, even though no interactions between maternal and offspring environments were found. Maternal effects were primarily exerted by the lipid content of the egg provisioned by the mother, which were largely independent of maternal treatment and population, and therefore rather general. Not all maternal effects could be readily interpreted adaptively, so some may merely reflect constraints of the mothers (Marshall \& Uller 2007). In addition to subtle maternal effects and previously known genetic differentiation in life-history traits along a latitudinal cline (Demont et al. 2008), the present study revealed heritable phenotypic plasticity as population (genotype) by (temperature and photoperiod) environment interactions, indicating adaptation to local climate. Yellow dung flies therefore can be expected to respond to environmental change via changes in direct and cross-generational plasticity as well as by local adaptation (Demont et al. 2008).

Acknowledgements. I.S. thanks W.U.B. and his lab members for their kind hosting during autumn of 2008. We also thank U. Briegel and B. Beck-Wörner for their great help throughout the experiment, C. Fox and D. Berger for comments, and J. Moya-Larano, A. Laugen, L. Bussière and A. Nilssen for help with collecting the flies. This research was supported by the Zoological Museum of the University of Zurich, the Swiss National Science Fund and the ESF ThermAdapt programme.

\section{LITERATURE CITED}

Abrams PA, Leimar S, Nylin S, Wiklund C (1996) The effect of flexible growth rates on optimal sizes and development times in a seasonal environment. Am Nat 147:381-395 
Amano K (1983) Studies on the intraspecific competition in dung breeding flies. I. Effects of larval density on the yellow dung fly. Jap J Sanit Zool 34:165-175

Angilletta MJ Jr, Steury TD, Sears MW (2004) Temperature, growth rate, and body size in ectotherms: fitting pieces of a life-history puzzle. Integr Comp Biol 44:498-509

> Azevedo RBR, French V, Partridge L (1997) Life-history consequences of egg size in Drosophila melanogaster. Am Nat 150:250-282

Bahrndorff S, Loeschke V, Pertoldi C, Beier C, Holmstrup M (2009) The rapid cold hardening response of Collembola is influenced by thermal variability of the habitat. Funct Ecol 23:340-347

Berrigan D, Scheiner SM (2004) Modeling the evolution of phenotypic plasticity. In: DeWitt TJ, Scheiner SM (eds) Phenotypic plasticity: functional and conceptual approaches. Oxford University Press, Oxford, p 82-97

Blanckenhorn WU (1994) Fitness consequences of alternative life histories in water striders, Aquarius remigis. Oecologia 97:354-365

Blanckenhorn WU (1997) Altitudinal life history variation in the dung fly Scathophaga stercoraria. Oecologia 109: $342-352$

Blanckenhorn WU (1998a) Altitudinal differentiation in the diapause response of two species of dung flies. Ecol Entomol 23:1-8

Blanckenhorn WU (1998b) Adaptive phenotypic plasticity in growth, development, and body size in the yellow dung fly. Evolution 52:1394-1407

Blanckenhorn WU (2000) Temperature effects on egg size and their fitness consequences in the yellow dung fly. Evol Ecol 14:627-643

Blanckenhorn WU (2002) The consistency of heritability estimates in field and laboratory in the yellow dung fly. Genetica 114:171-182

Blanckenhorn WU (2009) Causes and consequences of phenotypic plasticity in body size: the case of the yellow dung fly (Diptera: Scathophagidae). In: Whitman DW, Ananthakrishnan TN (eds) Phenotypic plasticity of insects: mechanisms and consequences. Science Publishers, Strixton, p 313-366

Blanckenhorn WU, Demont M (2004) Bergmann and converse Bergmann latitudinal clines in arthropods: two ends of a continuum? Integr Comp Biol 44:413-424

Blanckenhorn WU, Fairbairn DJ (1995) Life history adaptation along a latitudinal cline in water striders. J Evol Biol 8:21-41

Bradshaw WE, Holzapfel CM (2007) Evolution of animal photoperiodism. Annu Rev Ecol Evol Syst 38:1-25

> Canale CI, Henry PY (2010) Adaptive phenotypic plasticity and resilience of vertebrates to increasing climatic unpredictability. Clim Res 43:135-147

Chown SL, Hoffmann AA, Kristensen TN, Angilletta MJ Jr, Stenseth NC, Pertoldi C (2010) Adapting to climate change: a perspective from evolutionary physiology. Clim Res 43:3-15

> Crispo E (2008) Modifying effects of phenotypic plasticity on interactions among natural selection, adaptation and gene flow. J Evol Biol 21:1460-1469

Danks HV (1987) Insect dormancy: an ecological perspective. Biological Survey of Canada, Ottawa

> De Block M, Stoks R (2003) Adaptive sex-specific life history plasticity to temperature and photoperiod in a damselfly. J Evol Biol 16:986-995

> Demont M, Blanckenhorn WU (2008) Genetic differentiation in diapause reponse along a latitudinal cline in European yellow dung fly populations. Ecol Entomol 33:197-201
Demont M, Blanckenhorn WU, Hosken DJ, Garner TWJ (2008) Population and quantitative genetic differentiation across Europe in the yellow dung fly. J Evol Biol 21: 1492-1503

Denlinger DL (1998) Maternal control of fly diapause. In: Mousseau TA, Fox CW (eds) Maternal effects as adaptations. Oxford University Press, New York, p 275-287

Downer RGH, Matthews JR (1976) Patterns of lipid distribution and utilisation in insects. Am Zool 16:733-745

Fischer K, Karl I (2010) Exploring plastic and genetic responses to temperature variation using copper butterflies. Clim Res 43:17-30

> Foster W (1967) Hormone-mediated nutritional control of sexual behavior in male dung flies. Science 158:1596-1597

Fox CW, Czesak ME (2000) Evolutionary ecology of progeny size in arthropods. Annu Rev Entomol 45:341-369

Fox CW, Mousseau T (1998) Maternal effects as adaptations for transgenerational phenotypic plasticity in insects. In: Mousseau TA, Fox CW (eds) Maternal effects as adaptations. Oxford University Press, Oxford, p 159-177

Gomi T (1997) Geogrpahic variation in critical photoperiod for diapause induction and its temperature dependence in Hyphantria cunea Drury (Lepidoptera: Arctiidae). Oecologia 111:160-165

Gotthard K, Nylin S (1995) Adaptive plasticity and plasticity as an adaptation: a selective review of plasticity in animal morphology and life history. Oikos 74:3-17

Hairston NG Jr, Kearns CM (1995) The interaction of photoperiod and temperature in diapause timing: a copepod example. Biol Bull 189:42-48

Hanski I (1988) Four kinds of extra long diapause in insects: a review of theory and observations. Ann Zool Fenn 25: $37-53$

- Huey RB, Kingsolver JG (1989) Evolution of thermal sensitivity of ectotherm performance. Trends Ecol Evol 4:131-135

Jann P, Ward PI (1999) Maternal effects and their consequences for offspring fitness in the yellow dung fly. Funct Ecol 13:51-58

Kaplan RH (1998) Maternal effects, developmental plasticity and life history evolution. In: Mousseau TA, Fox CW (eds) Maternal effects as adaptations. Oxford University Press, Oxford, p 244-260

Kjærsgaard A, Faurby S, Krag K, Loeschcke V, Pertoldi C (2010) Temperature-maternal age interactions on wing traits in outbred Drosophila mercatorum. Clim Res 43:49-56

Liefting M, Ellers J (2008) Habitat-specific differences in thermal plasticity in natural populations of a soil arthropod. Biol J Linn Soc 94:265-271

Lüning J (1992) Phenotypic plasticity of Daphnia pulex in the presence of invertebrate predators: morphological and life history responses. Oecologia 92:383-390

> Marshall DJ, Uller T (2007) When is a maternal effect adaptive? Oikos 116:1957-1963

> McWatters HG, Saunders DS (1998) Maternal temperature has different effects on the photoperiodic response and duration of larval diapause in the blow fly (Calliphora vicina) strains collected at two latitudes. Physiol Entomol 23:369-375

> Minari O, Zilversmit DB (1963) Use of KNC for stabilization of color in direct Nesslerization of Kjerdahl digests. Anal Biochem 6:320-327

> Mousseau TA (1991) Geographic variation in maternal age effects on diapause in a cricket. Evolution 45:1053-1059

> Mousseau TA, Dingle H (1991) Maternal effects in insect life histories. Annu Rev Entomol 36:511-534

> Mousseau TA, Fox CW (1998) The adaptive significance of maternal effects. Trends Ecol Evol 13:403-407 
Murry BA, Farrell JM, Schultz KL, Teece MA (2008) The effect of egg size and nutrient content on larval performance: implications to protracted spawning in northern pike (Esox lucius Linnaeus). Hydrobiologia 601:71-82

Nylin S, Gotthard K (1998) Plasticity in life-history traits. Annu Rev Entomol 43:63-83

Pigliucci M (2005) Evolution of phenotypic plasticity: Where are we going now? Trends Ecol Evol 20:481-486

Räsänen K, Kruuk LEB (2007) Maternal effects and evolution at ecological time-scales. Funct Ecol 21:408-421

Reznick F, Travis J (2001) Adaptation. In: Fox CW, Roff DA, Fairbairn DJ (eds) Evolutionary ecology: concepts and case studies. Oxford University Press, Oxford, p 44-57

Schlichting CD (1986) The evolution of phenotypic plasticity in plants. Annu Rev Ecol Syst 17:667-693

Stillwell RC, Fox CW (2005) Complex patterns of phentoypic plasticity: interactive effects of temperature during rearing and oviposition. Ecology 86:924-934

Tachibana SI, Humata H (2004) Parental and direct effects of photoperiod and temperature on the induction of larval diapause in the blow fly Lucilia sericata. Physiol Entomol 29:39-44

Tauber MJ, Tauber CA, Masaki S (1986) Seasonal adapta-

Submitted: April 6, 2010; Accepted: July 6, 2010 tions of insects. Oxford University Press, Oxford

> Teuschl Y, Reim C, Blanckenhorn WU (2007) Correlated responses to artificial body size selection in growth, development, phenotypic plasticity and juvenile viability in yellow dung flies. J Evol Biol 20:87-103

- Van Buskirk J (2002) A comparative test of the adaptive plasticity hypothesis: relationships between habitat and phenotype in anuran larvae. Am Nat 160:87-102

Van Handel E (1985a) Rapid determination of total lipids in mosquitoes. J Am Mosq Control Assoc 1:299-301

- Van Handel E (1985b) Rapid determination of glycogen and sugars in mosquitoes. J Am Mosq Control Assoc 1: 302-303

> Van Handel E, Day JF (1988) Assay of lipids, glycogen and sugars in individual mosquitoes correlates with wing length in field-collected Aedes vexans. J Am Mosq Control Assoc 4:549-550

> van Tienderen PH (1997) Generalists, specialists, and the evolution of phenotypic plasticity in sympatric populations of distinct species. Evolution 51:1372-1380

> Via S, Lande R (1985) Genotype-environment interaction and the evolution of phenotypic plasticity. Evolution 39: $505-522$

Proofs received from author(s): July 23, 2010 